\title{
Intraperitoneal Bupivacaine-Meperidine Infiltration Versus Intravenous Paracetamol: A Comparison of Analgesic Efficacy in Post-Gynecologic Diagnostic Laparoscopic Pain
}

\author{
Sousan Rasooli ${ }^{1}$; Farnaz Moslemi ${ }^{1, *}$; Samad E. J. Golzari ${ }^{2}$ \\ ${ }^{1}$ Department of Anesthesiology, Alzahra Hospital, Tabriz University of Medical Sciences, Tabriz, Iran \\ ${ }^{2}$ Cardiovascular Research Center, Tabriz University of Medical Sciences, Tabriz, Iran \\ *Corresponding author: Farnaz Moslemi, Department of Anesthesiology, Alzahra Hospital, Tabriz University of Medical Sciences, Tabriz, Iran. Tel: +98-9143111715, Fax: +98-415566449, \\ E-mail: moslemifa@gmail.com
}

Received: December 27, 2014; Revised: February 25, 2015; Accepted: April 21, 2015

\begin{abstract}
Background: Pain following laparoscopy could be due to different causes requiring effective postoperative analgesia.
Objectives: In the present study, we evaluated the combined effect of intraperitoneal infiltration of bupivacaine-meperidine versus intravenous infusion of paracetamol on pain relief after diagnostic gynecologic laparoscopy.

Patients and Methods: In this prospective study, 90 female subjects with ASAclass I or II scheduled for gynecologic diagnostic laparoscopy were studied in two groups; group B + M received intraperitoneal infiltration of $40 \mathrm{~mL}$ bupivacaine $0.25 \%$ with 50 mg of meperidine, group $P$ received normal saline via abdominal trocar and ten minutes before the end of operation, group P received infusion of paracetamol $1000 \mathrm{mg}$ in normal saline. Postoperative pain was evaluated using VAS score in PACU and 1, 2, 4, 8, 12 and 24 hours after the operation. The time to the first analgesic administration and total analgesic requirements were recorded.

Results: Group B + M had significantly lower pain score in the first 8 postoperative hours than group $\mathrm{P}(\mathrm{P}<0.05)$. Rescue meperidine(IM) requirement was significantly less in $\mathrm{B}+\mathrm{M}$ group compared to group P. Time to first request for analgesia was different between the two groups (78 versus $60 \mathrm{~min}$ ); however, the difference was not statistically significant.

Conclusions: Intraperitoneal Infiltration of bupivacaine with meperidine following surgery provided more appropriate analgesia after gynecologic diagnostic laparoscopy than administration of IV paracetamol.
\end{abstract}

Keywords: Pain, Postoperative; Gynecologic Diagnostic Laparoscopy; Bupivacaine; Paracetamol; Meperidine; Meperidine

\section{Background}

The emergence of laparoscopic surgery decreased surgical exposure or trauma, manipulation of the intestines and the need for peritoneal incision. Furthermore, postoperative ileus and fasting duration and in-patient stay have been significantly diminished due to laparoscopy (1). Another advantage of laparoscopic surgery is a significant reduction in postoperative pain and hence the need for increased doses of analgesics. Pain after laparoscopy results from stretching of the intraabdominal cavity, peritoneal inflammation and phrenic nerve irritation caused by residual carbon dioxide in the peritoneal cavity $(2,3)$. The intensity and duration of postoperative pain is less after laparoscopic surgeries compared to laparotomy; however, moderate to severe pain could also exist (4). On the other hand, gynecologic diagnostic laparoscopy is currently considered a relatively minor operation and has been classified as a day-case surgery; yet an important factor limiting recovery is postoperative pain (5).

Considering varied mechanisms of post-laparoscopy pain, a safe multimodal perioperative analgesic regimen that provides effective pain relief with minimal side ef- fects is required. This pain can be reduced by early administration of analgesics, generally before awakening from general anesthesia (6-9). Preventive analgesia includes any intraoperative analgesic agents/techniques able to control pain-induced sensitization of the central nervous system and decrease the development of any persistent pain $(2,10,11)$.

Paracetamol (acetaminophen; N-acetyl-p-aminophenol) is a non-opioid analgesic devoid of risks related to opioids. Its clinical effects arise most likely from central action and intravenous administration provides rapid and predictable therapeutic plasma concentration $(12,13)$. The postoperative use of paracetamol has been shown to decrease acute pain after various surgical procedures $(12,13)$. Intraperitoneal (IP) administration of some drugs can be effective for relief of pain after laparoscopic surgery; local anesthetics and opioids can be given intraperitoneally $(11,14,15)$. Bupivacaine is an amide-type local anesthetic capable of producing prolonged analgesia (16). Meperidine has local anesthetic action on peripheral nerves in vivo. Multimodal analgesic regimens, i.e.

Copyright (C) 2015, Iranian Society of Regional Anesthesia and Pain Medicine(ISRAPM). This is an open-access article distributed under the terms of the Creative Commons Attribution-NonCommercial 4.0 International License (http://creativecommons.org/licenses/by-nc/4.0/) which permits copy and redistribute the material just in noncommercial usages, provided the original work is properly cited. 
Rasooli S et al.

administration of multiple analgesics rather than a single analgesic for minimizing the postoperative requirement, would allow more prompt postoperative recovery and therefore retaining normal daily activities. The combination of these two agents, used locally, may have some beneficial analgesic effects without any complication associated with the administration of intravenous drugs, especially IV opioids (13).

\section{Objectives}

The aim of this study was to compare analgesic effects of early premedication of two regimes with IV paracetamol and IP bupivacaine-meperidine to prevent pain following laparoscopy.

\section{Patients and Methods}

This randomized, double blind and placebo-controlled clinical trial was performed in Alzahra Obstetrics and Gynecology educational Hospital of Tabriz. The research protocol code was 92138 and the Registration ID in IRCT was IRCT2013072810765N4. After approval of the study from ethical committee of Tabriz University of Medical Sciences and obtaining informed written consent, 90 patients with ASA physical status I and II, aged 19 - 41 years, scheduled for Gynecologic Diagnostic Laparoscopy under general anesthesia, were randomly allocated to two groups (group $\mathrm{B}+\mathrm{M}, \mathrm{n}=45$; group $\mathrm{P}, \mathrm{n}=45$ ). Sample size calculation was performed using a 2-sided significant level of 0.05 and a power of $80 \%$ with $40 \%$ accuracy. In this study, P was calculated as 0.5 for Bupivacaine-Meperidine group and 0.9 for Paracetamol group. Patients with hepatic, vascular, metabolic or cardiac diseases and addiction to any drug or medication were excluded. Any patient with contraindications to meperidine, local anesthetics or paracetamol and any procedure longer than 1.5 hour were excluded. Patients were randomized according to a table of random numbers and the results were kept in sealed envelopes opened at induction time. A questionnaire including demographic, perioperative and postoperative characteristics was completed for each patient. After establishment of routine monitoring, including ECG, $\mathrm{SpO}_{2}$, noninvasive blood pressure control and capnography, all patients received $5 \mathrm{~mL} / \mathrm{kg}$ Ringer. A standardized total intravenous anesthesia technique (TIVA) was used for all patients. Both groups received midazolam $0.05 \mathrm{mg} / \mathrm{kg}$, fentanyl $2 \mu \mathrm{g} / \mathrm{kg}$ as premedication. Then, anesthesia induction was performed with propofol 1- $2.5 \mathrm{mg} / \mathrm{kg}$ and atracurium $0.5 \mathrm{mg} / \mathrm{kg}$. Subjects were intubated at minimum possible time using a suitable size tracheal tube or LMA and were connected to a ventilator with $\mathrm{O}_{2} 50 \%$ in air. Ventilation was adjusted to keep $\mathrm{ETCO}_{2}$ between 30 and $40 \mathrm{mmHg}$. No opioids were administered during the maintenance period. Anesthesia was maintained with propofol infusion $50-75 \mathrm{mg}$ $\mathrm{kg} / \mathrm{h}$. Residual effects of atracurium were reversed with neostigmine and atropine.
Diagnostic laparoscopy was performed in the usual manner with two reusable trocars. Carbon dioxide was used for insufflation. Intraabdominal pressure was maintained below $13 \mathrm{mmHg}$. Group B + M received intraperitoneal infiltration of $40 \mathrm{~mL}$ of bupivacaine $0.25 \%$ with meperidine $50 \mathrm{mg}$, and group P received equal volumes of normal saline through abdominal trocar at the end of procedure. Ten minutes before the end of operation, group P received infusion of paracetamol $1000 \mathrm{mg}$ in $100 \mathrm{~mL}$ normal saline during 15 minutes and group $\mathrm{B}+\mathrm{M}$ received infusion of equal volumes of only normal saline intravenously. For blinding the study, all drugs were prepared in covered syringes by a person other than the one administering the drugs. At the end of procedure, carbon dioxide was evacuated from the peritoneal cavity and trocars were removed. Pain intensity was assessed in PACU (10 minutes after patient's arrival to PACU) and at 1, 2, 4, 8, 12 and 24 hours after the operation using Visual Analogue Scale (VAS) ranging from no pain $(0 \mathrm{~cm})$ to the worst possible pain $(10 \mathrm{~cm})$. Prior to the operation, patients were instructed on how to use VAS. If the VAS score was greater than 4 , the patient was given $0.5 \mathrm{mg} / \mathrm{kg}$ IM meperidine and if the VAS score was 3 or 4 , received rectal diclofenac suppositories (75 $\mathrm{mg}$ ). The time to the first analgesia administration and total analgesic requirements in the first 24 hours were recorded. Postoperative complications, e.g. nausea and vomiting, shivering, respiratory depression or sedation, were controlled and recorded. Statistical analysis was performed using standard parametric and non-parametric statics. Independent sample t-test was used for parametric and MannWhitney U-test for nonparametric qualitative parameters. Qualitative data were compared with Chi-square test. All data were analyzed using SPSS version 17 (Version 17, Chicago, IL). $\mathrm{P}<0.05$ was considered statistically significant.

\section{Results}

Of 95 subjects entering the study, 5 were excluded at the beginning of study, 3 from group $B+M$ and 2 from group $P$ due to chronic pain and use of NSAIDs, uncontrolled hypertension or elevated blood sugar, respectively. One patient had a condition that required operative laparoscopy. There were no significant differences regarding age or weight between the studied groups. In addition, there were no differences in the duration of operation (Table 1 ).

The need for further analgesia was examined by measuring the number of patients who received either meperidine or diclofenac. Of note, $36.40 \%$ and $39.21 \%$ of patients in group B + M received supplementary meperidine and Diclofenac, respectively or both; whereas, $63.60 \%$ and $61.36 \%$ of patients in group $P$ received supplementary meperidine and Diclofenac, respectively. In group P, $15.2 \%$ of all patients received both diclofenac and meperidine according to VAS at the time of its assessment. Number of patients who received meperidine in group $\mathrm{P}$ was higher than group $\mathrm{B}+$ $\mathrm{M}$ (27 vs. 21) $(\mathrm{P}<0.0001)$. The average dose administered in those who received diclofenac in group $\mathrm{P}$ was higher than group $\mathrm{B}+\mathrm{M}$ (275 mg vs. $225 \mathrm{mg})(\mathrm{P}=0.0001)$. 
Rasooli S et al.

No statistically significant difference in VAS scores could be observed at VAS hours 1, 12, 24 between the two groups. Interestingly, VAS scores at hours 2, 4 and 8 were significantly less in group $\mathrm{B}+\mathrm{M}$ compared to group $\mathrm{P}(\mathrm{P}=0.002$, $\mathrm{P}=0.001, \mathrm{P}=0.034$, respectively). Further evaluation using Chi-Square test revealed that the overall difference between groups was significant; patients in group $\mathrm{B}+\mathrm{M}$ had lower VAS compared to group $\mathrm{P}(\mathrm{P}<0.001)$ (Table 2$)$.

Patients in group $\mathrm{B}+\mathrm{M}$ required a total of $25.49 \mathrm{mg}$ supplementary meperidine; whereas, patients in group $P$ required a total of $30.42 \mathrm{mg}$ supplementary meperidine ( $\mathrm{P}$ $=0.03$ ). The time to first analgesia requirement was also different between the two groups (78 vs. 60 min for B + $M$ vs. P, respectively); however, the difference was statistically insignificant.

The number of patients who had postoperative nausea and vomiting was 8 in the group B $+\mathrm{M}(17.8 \%)$ and 7 (15.6\%) in the group $\mathrm{P}$; the difference was not statistically significant. Two patients in group B $+\mathrm{M}(4.4 \%)$ and 6 patients in group $\mathrm{P}(22.2 \%)$ had sedation (1-2 of Aldrate score system). Eight patients in group $B+M$ and 6 patients in group $P$ experienced shivering.

\section{Discussion}

In the present study, administration of intraperitoneal bupivacaine + meperidine resulted in significantly lower pain scores than IV paracetamol, especially at early postoperative stages. Furthermore, additional analgesic requirement was significantly lower in bupivacaine + meperidine group subjects indicating the efficacy of this combination in reducing postoperative VAS and additional analgesic requirement.

Parsanezhad et al. in a comparative double-blind randomized study conducted on 134 female subjects undergoing diagnostic laparoscopy reported a significant pain relief both at early stages and 24 hours after the operation when bupivacaine was instilled in the peritoneal cavity and lidocaine was infiltrated into the trocar site. They recommended irrigation of bupivacaine to both hemi-diaphragm and pelvis at the completion of procedure (17). In this study, we used bupivacaine and meperidine intraperitoneally to achieve additional analgesic benefits from the combined effect of a local anesthetic with an opioid agonist. The effects of meperidine in our study may have been due to its systemic activity. The effects of meperidine appear to be produced by its actions on two independent pathways: the opioid receptor pathways, which induce analgesic action and the sodium channels, which are responsible for its local anesthetic action $(13,17)$.

In a study by Colbert and colleagues, the effect of intraperitoneal bupivacaine-meperidine was compared with the combination of intraperitoneal bupivacaine and IM meperidine for postoperative analgesia in 100 patients undergoing laparoscopic tubal ligation. In their study, administration of intraperitoneal meperidine resulted in significantly lower pain scores than the equivalent dose of meperidine administered IM. Although

Table 1. Clinical Characteristics and Operative Time in the Two Groups ${ }^{a}$

\begin{tabular}{lccc}
\hline Variable & ${\text { Group B }+\mathbf{M}^{\mathrm{b}, \mathrm{c}}}$ & Group P $^{\mathrm{c}, \mathrm{d}}$ & P Value $^{\mathrm{e}}$ \\
\hline Age, $\mathbf{y}$ & $29.00 \pm 6.18$ & $29.93 \pm 6.48$ & $\mathrm{P}=0.48$ \\
Weight, $\mathbf{K g}$ & $68.8 \pm 9.19$ & $68.22 \pm 9.19 \mathrm{~kg}$ & $\mathrm{P}=0.57$ \\
ASA class & $1.070 \pm 0.25$ & $1.09 \pm 0.28$ & $\mathrm{P}=0.205$ \\
Surgery time, min & $49.44 \pm 7.62$ & $53.11 \pm 7.25$ & $\mathrm{P}>0.05$ \\
\hline
\end{tabular}

a Data are summarized as Mean \pm Standard Deviation

b Group B + M: Bupivacaine + Meperidine.

c $\mathrm{n}=45$.

d Group P: Paracetamol.

e $\mathrm{P}<0.05$ is considered significant.

Table 2. Comparison of Postoperative Pain Scores Between the Two Groups a,b,c

\begin{tabular}{|c|c|c|c|}
\hline VAS & Group B + M & Group P & P Value \\
\hline 1 h later & $2.31 \pm 0.66$ & $2.37 \pm 0.63$ & 0.951 \\
\hline 2 h later & $2.75 \pm 0.98$ & $3.55 \pm 1.40$ & 0.002 \\
\hline $4 \mathrm{~h}$ & $2.60 \pm 0.65$ & $3.46 \pm 1.01$ & 0.001 \\
\hline $8 \mathrm{~h}$ & $1.53 \pm 1.32$ & $2.02 \pm 1.03$ & 0.034 \\
\hline $12 \mathrm{~h}$ & $1.11 \pm 0.43$ & $0.11 \pm 0.51$ & 0.513 \\
\hline $24 \mathrm{~h}$ & $0.02 \pm 0.14$ & $0.06 \pm 0.33$ & 0.551 \\
\hline
\end{tabular}

$\mathrm{a} n=45$.

b $\mathrm{P}<0.05$ is considered significant.

c Data are summarized as Mean \pm Standard Deviation. 
significant differences were observed in pain scores, no significant differences were observed for the time to additional analgesia and additional analgesia required during the study. They concluded that combination of IP bupivacaine-meperidine was better than the combination of intraperitoneal bupivacaine and IM meperidine for the relief of postoperative pain in women after laparoscopic tubal ligation (18).

In our study, the pain scores were significantly lower in patients who received intraperitoneal bupivacainemeperidine in comparison with females who received paracetamol. In a study by Hemida et al. the analgesic efficacy of intraperitoneal ropivacaine plus intravenous paracetamol was compared with single intravenous paracetamol for laparoscopic cholecystectomy; it was concluded that this combination provides a superior analgesia (19). In contrast, Gousheh et al. showed that although intravenous paracetamol resulted in a better pain relief quality, it was not a suitable sole analgesic for moderate pain control in acute phase following surgery (20). Moreover, the survey of Jabbour-Khoury et al. focusing on different intraperitoneal and intravenous routes for pain relief after laparoscopy, indicated that a multimodal approach for pain management is best achieved with combination of intraperitoneal infiltration and intravenous route (21). Likewise, our study revealed that intravenous administration of one drug such as paracetamol is not sufficient to control relatively severe pain after laparoscopy and a combination therapy including intraperitoneal infiltration of medications with different analgesic mechanisms appears to have much better pain relief with less additional analgesic requirement, especially opioids requirement which in turn could lead to undesirable complications. The limitation of our study was that although it was conducted on diagnostic laparoscopy procedures, the final diagnosis of some patients was endometriosis. Consequently some patients underwent ovarian cauterization. Therefore, the severity of pain could have been slightly different between patients, limiting the accurate assessment of pain scoring.

Administration of intraperitoneal bupivacaine-meperidine after diagnostic gynecologic laparoscopic procedures was more effective in pain control than IV paracetamol, especially in the first six hours postoperatively. This combination is simple to use and it significantly decreases early postoperative pain, reducing the need for additional postoperative analgesics.

\section{Authors' Contributions}

Sousan Rasooli designed the study and collected data. Farnaz Moslemi collected data and prepared the draft of study. Samad E. J. Golzari collected data, performed the study analysis and finalized the study.

\section{Funding/Support}

This research was the result of a thesis and supported by Tabriz University of Medical Sciences, Tabriz, Iran.

\section{References}

1. Abdollahi SF, Bahlouli A, Mostafa PG, Rasooli S, Morteza G. Comparison of laparoscopy-assisted hysterectomies with conventional hysterectomies. Saudi Med J. 2009;30(6):813-6.

2. Alexander JI. Pain after laparoscopy. Br J Anaesth. 1997;79(3):369-78.

3. Gibbison B, Kinsella SM. Postoperative analgesia for gynecological laparoscopy. Saudi J Anaesth. 2009;3(2):70-6.

4. Maharjan SK, Shrestha S. Intraperitoneal and periportal injection of bupivacaine for pain after laparoscopic cholecystectomy. Kathmandu Uni Med J. 2009;7(1)

5. Golubovic S, Golubovic V, Cindric-Stancin M, Tokmadzic VS Intraperitoneal analgesia for laparoscopic cholecystectomy: bupivacaine versus bupivacaine with tramadol. Coll Antropol. 2009;33(1):299-302.

6. Moiniche S, Kehlet H, Dahl JB. A qualitative and quantitative systematic review of preemptive analgesia for postoperative pain relief: the role of timing of analgesia. Anesthesiology. 2002;96(3):725-41.

7. Ong CK, Lirk P, Seymour RA, Jenkins BJ. The efficacy of preemptive analgesia for acute postoperative pain management: a metaanalysis. Anesth Analg. 2005;100(3):757-73.

8. Adachi YU, Nishino J, Suzuki K, Obata Y, Doi M, Sato S. Preemptive analgesia by preoperative administration of nonsteroidal antiinflammatory drugs. J Anesth. 2007;21(2):294.

9. Soleimanpour H, Hassanzadeh K, Vaezi H, Golzari SE, Esfanjani RM, Soleimanpour M. Effectiveness of intravenous lidocaine versus intravenous morphine for patients with renal colic in the emergency department. BMC Urol. 2012;12:13.

10. Holmer Pettersson P, Owall A, Jakobsson J. Early bioavailability of paracetamol after oral or intravenous administration. Acto Anaesthesiol Scand. 2004;48(7):867-70.

11. Ziyaeifard M, Azarfarin R, Golzari SE. A Review of Current Analgesic Techniques in Cardiac Surgery. Is Epidural Worth it? J Cardiovasc Thorac Res. 2014;6(3):133-40.

12. Moon YE, Lee YK, Lee J, Moon DE. The effects of preoperative intravenous acetaminophen in patients undergoing abdominal hysterectomy. Arch Gynecol Obstet. 2011;284(6):1455-60.

13. Eydi M, Golzari SE, Aghamohammadi D, Kolahdouzan K, Safari S, Ostadi Z. Postoperative Management of Shivering: A Comparison of Pethidine vs. Ketamine. Anesth Pain Med. 2014;4(2):e15499.

14. Elhakim M, Elkott M, Ali NM, Tahoun HM. Intraperitoneal lidocaine for postoperative pain after laparoscopy. Acta Anaesthesiol Scand. 2000;44(3):280-4.

15. El-Sherbiny W, Saber W, Askalany AN, El-Daly A, Sleem AA. Effect of intra-abdominal instillation of lidocaine during minor laparoscopic procedures. Int J Gynaecol Obstet. 2009;106(3):213-5.

16. Armstrong PJ, Morton CP, Nimmo AF. Pethidine has a local anaesthetic action on peripheral nerves in vivo. Addition to prilocaine $0.25 \%$ for intravenous regional anaesthesia in volunteers. Anaesthesia. 1993;48(5):382-6.

17. Parsanezhad ME, Lahsaee M, Alborzi S, Vafaei H, Schmidt EH Comparative, double-blind, randomized, placebo-controlled trial of intraperitoneal of bupivacaine and lidocaine for pain control after diagnostic laparoscopy. J Am Assoc Gynecol Laparosc. 2003;10(3):311-5.

18. Colbert ST, Moran K, O'Hanlon DM, Chambers F, Moriarty DC Blunnie WP. An assessment of the value of intraperitoneal meperidine for analgesia postlaparoscopic tubal ligation. Anesth Analg. 2000;91(3):667-70.

19. Hemida MRDN, Hazem AH, Al-Korashy SA. Analgesic Efficacy of Interaperitoneal Ropivacaine or Combined with Intravenous Paracetamol for Laparoscopic Cholecystectomy. Tanta Med Sci J. 2006;1:140-9.

20. Gousheh SM, Nesioonpour S, Javaher Foroosh F, Akhondzadeh $\mathrm{R}$, Sahafi SA, Alizadeh Z. Intravenous paracetamol for postoperative analgesia in laparoscopic cholecystectomy. Anesth Pain Med. 2013;3(1):214-8.

21. Jabbour-Khoury SI, Dabbous AS, Gerges FJ, Azar MS, Ayoub CM Khoury GS. Intraperitoneal and intravenous routes for pain relief in laparoscopic cholecystectomy. JSLS. 2005;9(3):316-21. 